\title{
Inhibitory effects of dieckol on hypoxia-induced epithelial-mesenchymal transition of HT29 human colorectal cancer cells
}

\author{
SEUNG-HYUN JEONG ${ }^{1}$, YOU-JIN JEON ${ }^{2}$ and SUN JOO PARK ${ }^{1}$ \\ ${ }^{1}$ Department of Chemistry, Pukyong National University, Busan 608-737; ${ }^{2}$ Department of Marine Life Science, \\ Jeju National University, Jeju 690-756, Republic of Korea
}

Received September 4, 2015; Accepted October 7, 2016

DOI: $10.3892 / \mathrm{mmr} .2016 .5872$

\begin{abstract}
Hypoxia-induced epithelial-mesenchymal transition (EMT) has been identified as essential for tumor progression and metastasis. The present study examined the effects of an antioxidant, dieckol, on hypoxia-induced EMT in HT29 human colorectal cancer cells. HT29 cells were treated with a hypoxia-inducing agent, $\mathrm{CoCl}_{2}$, and an increase in the levels of intracellular reactive oxygen species (ROS) and various morphological changes, such as loss of cell-cell contact and aggressive cell migration were observed. $\mathrm{CoCl}_{2}$ also induced an increase in the expression of hypoxia-inducible factor $1 \alpha$ (HIF1 $\alpha$ ) and various mesenchymal-specific markers, including vimentin and snail family transcriptional repressor 1 (Snail1), and a decrease in the expression of E-cadherin, thus suggesting that $\mathrm{CoCl}_{2}$ induced EMT in HT29 cells. Conversely, the $\mathrm{CoCl}_{2}$-induced EMT of HT29 cells was suppressed following treatment with dieckol. In addition, ROS generation, EMT marker protein expression and intracellular localization, cell migration and cell invasion were attenuated following dieckol treatment. The findings of the present study suggested that dieckol may inhibit hypoxia-induced EMT in HT29 cells by regulating the levels of cellular ROS and protein expression levels downstream of the HIF1 $\alpha$ signaling pathway. Therefore, dieckol has the potential to become an attractive therapeutic agent for the treatment of colorectal cancer.
\end{abstract}

\section{Introduction}

Hypoxia frequently occurs in a wide range of solid tumors. Hypoxia is responsible for the promotion of tumor motility, invasion and metastasis, genomic instability and cell survival

Correspondence to: Professor Sun Joo Park, Department of Chemistry, Pukyong National University, 599-1 Daeyeon 3-Dong, Nam-Gu, Busan 608-737, Republic of Korea

E-mail: parksj@pknu.ac.kr

Key words: dieckol, hypoxia, epithelial-mesenchymal transition, reactive oxygen species, invasion, migration responses, through the regulation of gene expression downstream of hypoxia-inducible factor 1 (HIF1) (1-3). HIF1 is a heterodimeric transcription factor composed of an ' $\alpha$ ' and a ' $\beta$ ' subunit. HIF1 $\alpha$ is a cytoplasmic protein responsive to $\mathrm{O}_{2}$ levels, whereas HIF1 $\beta$ is a nuclear protein, which is constitutively expressed independent of $\mathrm{O}_{2}$ levels. Under hypoxic conditions, HIF1 $\alpha$ is translocated to the nucleus where it forms a heterodimer with HIF1 $\beta$ subunits, resulting in the activation of HIF1 and its complex downstream genetic program, which may be responsible for numerous hypoxia-associated cellular changes (4). Hypoxia has been identified to promote metastasis of tumor cells by induction of epithelial-mesenchymal transition (EMT) $(5,6)$. EMT is a process by which epithelial cells lose their cell polarity and cell-cell adhesion, and gain migratory and invasive properties, thus becoming mesenchymal stem cells. Therefore, EMT is an essential process that results in tumor metastasis. At the molecular level, EMT is characterized by decreases in the expression levels of epithelial markers, such as E-cadherin, and an increase in mesenchymal markers, such as vimentin and snail family transcriptional repressor 1 (Snail1), as well as an increase in migratory and invasive behavior (7-9). Under hypoxic conditions, expression of the EMT marker proteins has previously been observed to be mutually dependent on the expression and activation of $\operatorname{HIF} 1 \alpha(8,9)$.

Previous studies have demonstrated that hypoxia stimulates the production of reactive oxygen species (ROS) in tumor cells and hypoxia-generated intracellular ROS may activate and stabilize HIF1 $\alpha$, thus contributing to tumor growth and metastasis, in addition to tumor recurrence and therapeutic resistance (10-13). In this regard, ROS-induced HIF1 $\alpha$ activation may be a major target for future cancer therapeutic approaches.

The present study examined the effects of hypoxia-induced intracellular ROS on the EMT of HT29 human colorectal cancer cells in the presence or absence of the antioxidant dieckol. The hypoxia-inducing agent, $\mathrm{CoCl}_{2}$ was used to induce an increase in ROS levels and HIF1 $\alpha$ expression in HT29 cells, and led to the transition of cellular phenotypes, corresponding to the fundamental events in EMT. These effects were markedly attenuated following dieckol treatment. Therefore, the present study demonstrated that ROS-induced activation of HIF1 $\alpha$ was a key factor contributing to the induction of EMT in HT29 cells. 


\section{Materials and methods}

Cell culture and reagents. HT29 human colorectal cancer cells, obtained from the American Type Culture Collection (Manassas, VA, USA), were cultured in Dulbecco's modified Eagle's medium (DMEM; Gibco; Thermo Fisher Scientific, Inc., Waltham, MA, USA), supplemented with $10 \%$ heat-inactivated fetal bovine serum (FBS; Gibco; Thermo Fisher Scientific, Inc.), $100 \mathrm{U} / \mathrm{ml}$ penicillin and $100 \mathrm{mg} / \mathrm{ml}$ streptomycin, in a $5 \% \mathrm{CO}_{2}$ atmosphere at $37^{\circ} \mathrm{C}$. For the cell-culture experiments, cells were passaged three times and detached using Trypsin-EDTA. Transwell migration and Matrigel invasion chambers were purchased from BD Biosciences (Franklin Lakes, NJ, USA). Primary antibodies against HIF1 $\alpha$ (cat. no. 610958), E-cadherin (cat. no. 7870), vimentin (cat. no. 5741), Snail1 (cat. no. AV33314) and $\beta$-actin (cat. no. MAB1501) were obtained from BD Biosciences, Santa Cruz Biotechnology, Inc. (Dallas, TX, USA), Cell Signaling Technology, Inc. (Danvers, MA, USA), and Sigma-Aldrich; Merck Millipore (Darmstadt, Germany), respectively. Dihydroethidium (DHE) was obtained from Molecular Probes (Thermo Fisher Scientific, Inc.). Dieckol was prepared as previously described by Lee et al (14). All remaining chemicals and reagents were purchased form Sigma-Aldrich; Merck Millipore, unless stated otherwise.

Cell viability assay. The cytotoxicity of $\mathrm{CoCl}_{2}$ and/or dieckol was determined using the 3-(4, 5-dimetylthiazol-2-yl)-2,5-diphenyltetrazolium bromide (MTT) formazan assay. HT29 cells were seeded in 12-well plates at a density of $2.0 \times 10^{5}$ cells/well in DMEM containing $10 \%$ FBS. The medium was changed $36 \mathrm{~h}$ after seeding to serum-free low glucose $(1,000 \mathrm{mg} / \mathrm{l})$ DMEM and the cells were incubated with $0-200 \mu \mathrm{M} \mathrm{CoCl}_{2}$ for $36 \mathrm{~h}$. The cells were then incubated with or without 0-100 $\mathrm{mg} / \mathrm{ml}(0-216 \mu \mathrm{M})$ dieckol for $12 \mathrm{~h}$. Subsequently, the medium was carefully removed and $160 \mu \mathrm{l}$ MTT $(0.5 \mathrm{mg} / \mathrm{ml}$ final concentration) solution was added to each well prior to incubation for an additional $4 \mathrm{~h}$ at $37^{\circ} \mathrm{C}$ in $5 \% \mathrm{CO}_{2}$. The medium was aspirated without the formazan crystals and $1 \mathrm{ml}$ dimethyl sulfoxide was added to each well. The absorbance was then measured using a microplate reader (iMark; Bio-Rad Laboratories, Inc., Hercules, CA, USA) at $540 \mathrm{~nm}$.

Cell migration and invasion assay. Cell migration was determined using a Transwell chamber. HT29 cells were treated with or without $50 \mu \mathrm{M} \mathrm{CoCl}_{2}$ in serum-free low glucose $(1,000 \mathrm{mg} / \mathrm{l}) \mathrm{DMEM}$ for $24 \mathrm{~h}$. The cells were trypsinized and collected. Subsequently, $300 \mu \mathrm{l}$ cell suspension $\left(1.5 \times 10^{5}\right.$ cells $)$ was incubated at $37^{\circ} \mathrm{C}$ in serum-starved DMEM containing $50 \mu \mathrm{M} \mathrm{CoCl}_{2}$ and/or $25 \mathrm{mg} / \mathrm{ml}$ dieckol and added to the upper compartment of the Transwell chamber in a humidified atmosphere with $5 \% \mathrm{CO}_{2}$ for $24 \mathrm{~h}$. DMEM containing $10 \%$ FBS was used as a chemoattractant in the lower compartment. Following a $24 \mathrm{~h}$ incubation at $37^{\circ} \mathrm{C}$, cells on the upper surface of the membrane were removed and the cells that had migrated below the surface of the membrane were fixed with $3.7 \%$ formaldehyde in phosphate-buffered saline (PBS), stained with crystal violet (1 g dissolved in $10 \%$ ethanol) for 30 min, washed twice with PBS and counted under a phase contrast microscope using a 10x objective lens. The number of migrated cells in five randomly selected fields were counted. The migration assays were performed in triplicate.

For the invasion assay, cells were seeded in the Transwell invasion chambers, which were coated with Matrigel $(1 \mathrm{mg} / \mathrm{ml})$. DMEM supplemented with $10 \%$ FBS was added to the lower compartment of the chamber. Cells were serum-starved and treated with $50 \mu \mathrm{M} \mathrm{CoCl}_{2}$ and/or $25 \mathrm{mg} / \mathrm{ml} \mathrm{dieckol} \mathrm{as} \mathrm{afore-}$ mentioned, then trypsinized and collected. Subsequently, $300 \mu \mathrm{l}$ of each cell suspension was added to the upper compartment of the chamber and incubated at $37^{\circ} \mathrm{C}$ in a humidified atmosphere with $5 \% \mathrm{CO}_{2}$ for $24 \mathrm{~h}$. Cells that had invaded below the surface of the membrane were fixed, stained, washed, and counted. The number of cells in five randomly selected fields was counted. The invasion assays were performed in triplicate.

ROS quantification. HT29 cells $\left(2.0 \times 10^{5}\right.$ cells/well) were serum-starved for $24 \mathrm{~h}$ and were then incubated in the presence or absence of $50 \mu \mathrm{M} \mathrm{CoCl}_{2}$ for $36 \mathrm{~h}$, with the medium being replaced twice, followed by treatment with or without $25 \mathrm{mg} / \mathrm{ml}$ dieckol for $3 \mathrm{~h}$. Cellular ROS levels were determined using DHE staining and the Muse oxidative stress kit (Merck Millipore) according to the manufacturer's protocol.

Western blotting. Following the aforementioned treatments, cells were washed twice with PBS, harvested and solubilized in $2 \mathrm{X}$ sodium dodecyl sulfate (SDS) protein sample buffer containing $100 \mathrm{mM}$ Tris-HCl (pH 6.8), 200 mM DTT, 4 SDS, $0.4 \%$ bromophenol blue, and $20 \%$ glycerol. Protein was quantified using the Bradford Protein assay kit II (Bio-Rad Laboratories, Inc.). Equal quantities of protein $(25 \mu \mathrm{g})$ were separated by $10 \%$ SDS-polyacrylamide gel electrophoresis. The resolved proteins were then transferred to polyvinyldifluoride membranes (Merck Millipore). The membranes were blocked by incubation with $1 \%$ bovine serum albumin in TBS-Tween-20 (TBST; $10 \mathrm{mM}$ Tris- $\mathrm{HCl}, 150 \mathrm{mM} \mathrm{NaCl}$ $\mathrm{pH} 7.5$ containing $0.1 \%$ Tween-20) at room temperature for $1 \mathrm{~h}$ and were then incubated with primary antibodies against HIF1 $\alpha$ (1:500), E-cadherin (1:200), vimentin (1:500), Snail1 $(1: 200)$ and $\beta$-actin $(1: 1,000)$ for $1 \mathrm{~h}$ at room temperature. The membranes were washed three times with TBST and were then incubated for $30 \mathrm{~min}$ with goat anti-rabbit or goat anti-mouse secondary antibody conjugated to alkaline phosphatase (1:1,000; Santa Cruz Biotechnology, Inc.; cat. nos. sc-2007 and sc-2008). The respective proteins were detected by colorimetric reactions using 5-bromo-4-chloro-3'-indolyphosphate/nitro-blue tetrazolium substrate.

Cell morphology and immunofluorescence assay. Cells were collected at different time points $(2-48 \mathrm{~h}$ ) for analysis of cell morphological changes and at $48 \mathrm{~h}$ for immunofluorescence and were fixed in $3.7 \%$ formaldehyde for $5 \mathrm{~min}$. Fixed cells were permeabilized in $0.1 \%$ Triton X-100 and were incubated with antibodies specific to E-cadherin (1:200), vimentin (1:100), and Snail1 (1:100) for $1 \mathrm{~h}$ at room temperature. The cells were then washed and incubated with secondary antibodies for $30 \mathrm{~min}$ at room temperature. Immunostaining was detected using the goat anti-mouse and goat anti-rabbit secondary antibodies labeled with Alexa Fluor 488 (1:500; Molecular Probes; Thermo Fisher Scientific, Inc.; cat. nos. A11029 and A11034). Actin was stained using rhodamine phalloidin (Thermo Fisher 
Scientific, Inc.). Cells were examined using the Zeiss LSM 510 confocal imaging system (Carl Zeiss, Oberkochen, Germany).

Statistical analysis. Data were analyzed using InStat statistics software version 6.0 (GraphPad Software, Inc., La Jolla, CA, USA). Statistical comparisons were performed using one-way analysis of variance followed by Bonferroni post-hoc test for multiple comparisons. $\mathrm{P}<0.05$ was considered to indicate a statistically significant difference.

\section{Results}

Dieckol attenuates $\mathrm{CoCl}_{2}$-induced intracellular ROS levels in HT29 cells. Previous studies have suggested that hypoxia may stimulate the generation of ROS in tumor cells, and increased ROS promotes tumor progression; however, details of the underlying molecular mechanism remain to be elucidated (10-13). The investigation of ROS levels in tumor cells and antioxidants as potential dietary supplements for the prevention of tumor progression and potential cancer treatment has grown rapidly. The present study used HT29 human colorectal cancer cells to assess the association between hypoxia-induced intracellular ROS generation and tumor progression. $\mathrm{CoCl}_{2}$ was used as a reagent to mimic the hypoxic microenvironment of tumor cells $(8,15) . \mathrm{CoCl}_{2}$ and dieckol did not affect the viability of HT29 cells at concentrations below $100 \mu \mathrm{M}$ and $25 \mathrm{mg} / \mathrm{ml}(54 \mu \mathrm{M})$, respectively (Fig. 1). As presented in Fig. 2, treatment of HT29 cells with $50 \mu \mathrm{M} \mathrm{CoCl}_{2}$ resulted in significantly increased intracellular ROS levels to $\sim 140 \%$ compared with the control ( $\mathrm{P}<0.05$; Fig. $2 \mathrm{~B})$, suggesting that $\mathrm{CoCl}_{2}$ successfully mimicked the hypoxic environment of tumor cells. In addition, in order to determine whether intracellular ROS levels were associated with hypoxia-induced tumor progression, HT29 cells were treated with $25 \mathrm{mg} / \mathrm{ml}$ dieckol in the absence and presence of $50 \mu \mathrm{M} \mathrm{CoCl}_{2}$ treatment. Dieckol treatment significantly attenuated the $\mathrm{CoCl}_{2}$-induced increased cellular ROS levels ( $\mathrm{P}<0.05 ;$ Fig. 2B). These findings suggest that HT29 cells may be responsive to $\mathrm{CoCl}_{2}$-induced hypoxia and the antioxidant dieckol effectively reduced the $\mathrm{CoCl}_{2}$-induced intracellular ROS levels.

Dieckol inhibits $\mathrm{CoCl}_{2}$-induced EMT-associated phenotypic changes of HT29 cells. The effects of hypoxia-induced intracellular ROS on the EMT of HT29 cells were also examined.EMT is characterized by epithelial cells acquiring a mesenchymal appearance, such as the loss of cell-cell contact, scattering from cell clusters, acquisition of mesenchymal properties and the downregulation of epithelium-specific proteins, such as E-cadherin, while simultaneously expressing mesenchymal proteins such as vimentin and Snail1. As presented in Fig. 3A, HT29 cells displayed typical epithelial characteristics with well-developed cell-cell contact in the control group, without $\mathrm{CoCl}_{2}$ treatment, whereas $\mathrm{HT} 29$ cells subjected to $50 \mu \mathrm{M} \mathrm{CoCl}_{2}$ had reduced cell-cell contact and formed scattered clusters. To examine whether the morphological changes in $\mathrm{CoCl}_{2}$-treated HT29 cells were consistent with EMT, immunofluorescence microscopy was performed, examining E-cadherin, an epithelial cell marker, and vimentin and Snaill, mesenchymal cell markers. As presented in Fig. 3B-D, E-cadherin signaling was primarily localized at the cell-cell contact area in the control
A
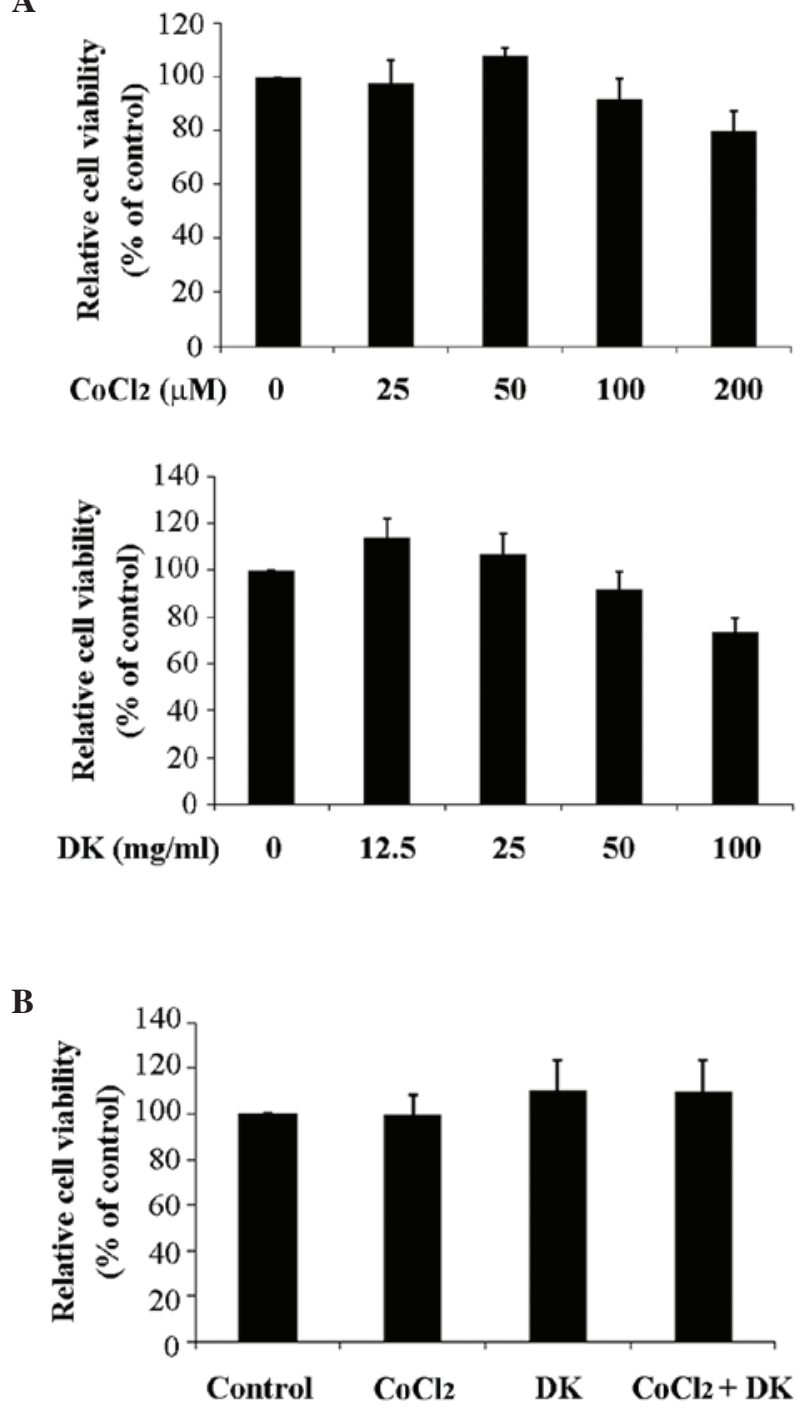

Figure 1. Effects of $\mathrm{CoCl}_{2}$ and DK on viability of HT29 cells. (A) HT29 cells were treated with various $\mathrm{CoCl}_{2}$ or DK concentrations for $48 \mathrm{~h}$ and were then assessed using an MTT assay. (B) HT29 cells were treated with $50 \mu \mathrm{M}$ $\mathrm{CoCl}_{2}$ and/or $25 \mathrm{mg} / \mathrm{ml}(54 \mu \mathrm{M}) \mathrm{DK}$ for $48 \mathrm{~h}$. All data are presented as the mean \pm standard deviation from three independent experiments. DK, dieckol.

group (without $\mathrm{CoCl}_{2}$ treatment). Following treatment with $50 \mu \mathrm{M} \mathrm{CoCl}_{2}$ E-cadherin levels were decreased and diffused throughout the cytoplasm, whereas nuclear vimentin signaling was dispersed to the cytoplasm and membrane fraction. Nuclear translocation of the transcription factor Snaill was clearly observed (Fig. 3D), suggesting that the morphological changes observed in $\mathrm{CoCl}_{2}$-treated HT29 cells may be identified as the onset of EMT. Cells were treated with $50 \mu \mathrm{M} \mathrm{CoCl}_{2}$ in order to determine whether $\mathrm{CoCl}_{2}$-induced intracellular ROS levels were associated with EMT and subsequently incubated in the presence or absence of $25 \mathrm{mg} / \mathrm{ml}$ dieckol. Dieckol treatment inhibited the $\mathrm{CoCl}_{2}$-induced mesenchymal morphologic changes and the redistribution of E-cadherin, vimentin and Snaill, indicating that the $\mathrm{CoCl}_{2}$-induced increase in ROS levels may be associated with the occurrence of EMT in HT29 cells.

Dieckol decreases $\mathrm{CoCl}_{2}$-induced migration and invasion of HT29 cells. EMT promotes the migration and invasion 
A
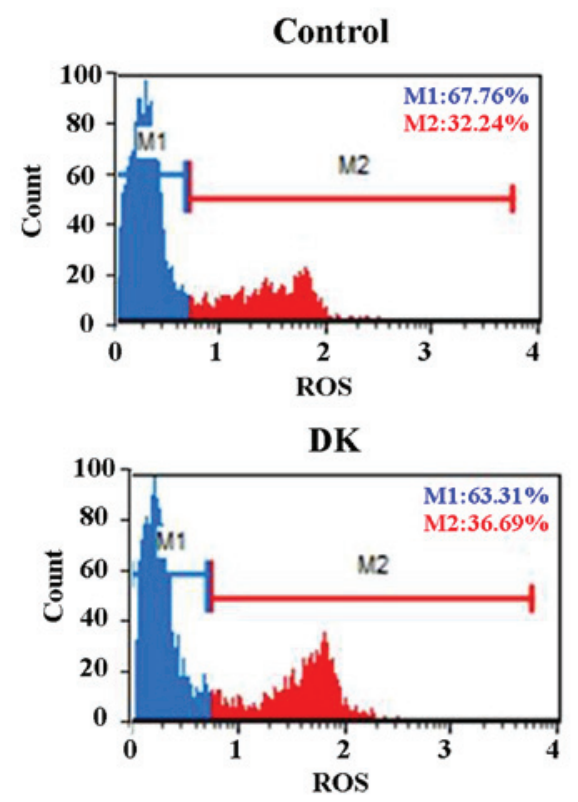
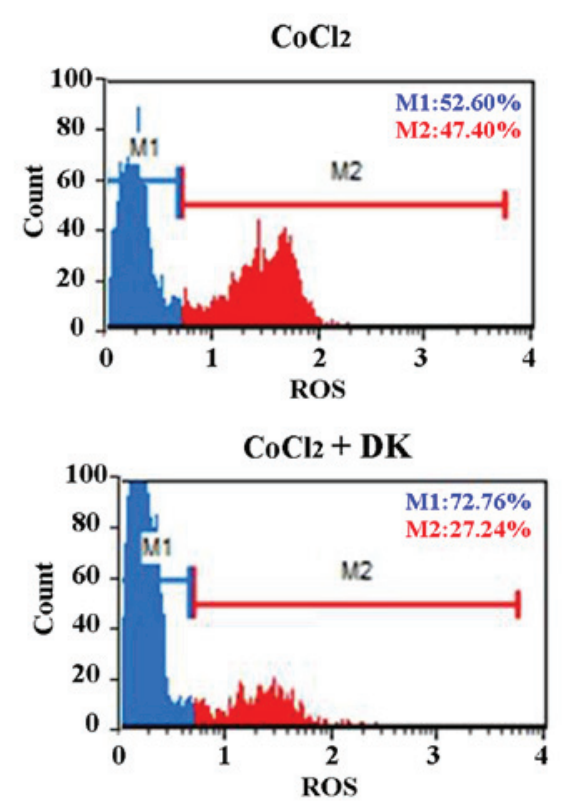

B

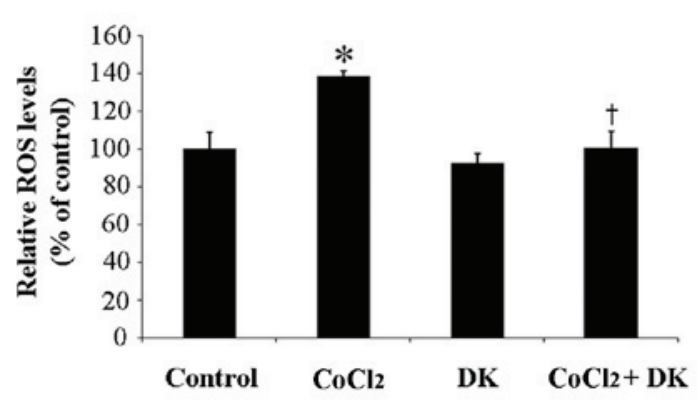

Figure 2. DK attenuated $\mathrm{CoCl}_{2}$-induced ROS levels in HT29 cells. (A) HT29 cells $\left(2 \times 10^{5}\right.$ cells) were serum starved and then incubated in the presence or absence of $50 \mu \mathrm{M} \mathrm{CoCl}_{2}$ for $36 \mathrm{~h}$ with medium replaced twice, followed by treatment with or without $25 \mathrm{mg} / \mathrm{ml} \mathrm{DK}$ for $3 \mathrm{~h}$. Cellular ROS levels were determined by dihydroethidium staining and flow cytometry. (B) Quantification of ROS levels in the different treatment groups. All data are presented as the mean \pm standard deviation from three independent experiments. ${ }^{*} \mathrm{P}<0.05$ vs. control group; ${ }^{\dagger} \mathrm{P}<0.05$ vs. $\mathrm{CoCl}_{2}$ group. DK, dieckol; ROS, reactive oxygen species.

of cancer cell (5-7). In order to investigate the effects of $\mathrm{CoCl}_{2}$-induced hypoxia on migration and invasion of HT29 cells, the migration of HT29 cells was examined using Transwell chambers. DMEM with $10 \%$ FBS was used as a chemoattractant in the lower chamber. As presented in Fig. 4A, treatment with $50 \mu \mathrm{M} \mathrm{CoCl}_{2}$ significantly increased migration of HT29 cells by $\sim 1.7$-fold compared with the control $(\mathrm{P}<0.05)$, suggesting that $\mathrm{CoCl}_{2}$-induced hypoxia may be associated with increased HT29 cell migration. However, when HT29 cells were treated with $25 \mathrm{mg} / \mathrm{ml}$ dieckol following incubation with $\mathrm{CoCl}_{2}$, the $\mathrm{CoCl}_{2}$-induced increased migration of cells was significantly inhibited $(\mathrm{P}<0.05$; Fig. 4A). Invasion of HT29 cells on reconstituted 3D Matrigel matrix significantly increased by $\sim 1$.4-fold in the presence of $\mathrm{CoCl}_{2}$ compared with the control group $(\mathrm{P}<0.05$; Fig. $4 \mathrm{~B})$ and subsequent treatment with dieckol significantly inhibited the $\mathrm{CoCl}_{2}$-induced invasive motility of cells $(\mathrm{P}<0.05$; Fig. 4B). These findings suggest that the reduction of intracellular ROS levels following dieckol treatment may decrease the hypoxia-induced migration and invasion of HT29 cells.

Dieckol suppresses the HIFla signaling pathway, required for $\mathrm{CoCl}_{2}$-induced EMT of HT29 cells. Subsequently, the
$\mathrm{CoCl}_{2}$-induced morphological changes and increased cell motility of HT29 cells were verified by quantification of the changes in the intracellular expression levels of EMT marker proteins. As aforementioned, EMT is initially characterized by the downregulation of the epithelial marker, E-cadherin, and by an upregulation of mesenchymal markers, such as vimentin. In particular, under hypoxia-induced EMT, selective transcription factors HIF1 $\alpha$ and Snaill are major factors in regulating the expression of EMT marker proteins (8). Previous studies silenced HIF1 $\alpha$ by RNA interference (RNAi), which resulted in an increase in E-cadherin, a decrease in vimentin and reduced cell invasion (16,17). The HIF1 $\alpha$-dependent regulation of E-cadherin expression is induced by upregulation of Snail1 $(18,19)$. Silencing of HIF1 $\alpha$ reduced nuclear localization of Snail1, which resulted in increased E-cadherin expression. In accordance with these reports, when HT29 cells were cultured in $50 \mu \mathrm{M} \mathrm{CoCl}_{2}$, HIF1 $\alpha$ expression levels increased (Fig. 5). Expression levels of vimentin and Snaill were also increased, whereas the expression of E-cadherin was decreased. Conversely, dieckol treatment reversed the $\mathrm{CoCl}_{2}$-induced changes in expression levels of all EMT marker proteins. These findings suggest that ROS levels and HIF1 $\alpha$ signaling are important for $\mathrm{CoCl}_{2}$-induced EMT in HT29 cells. 
A

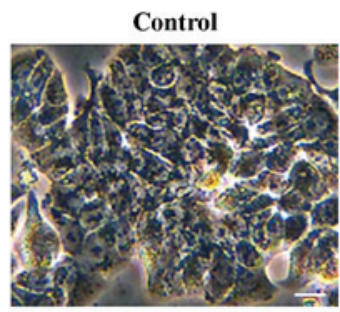

DK

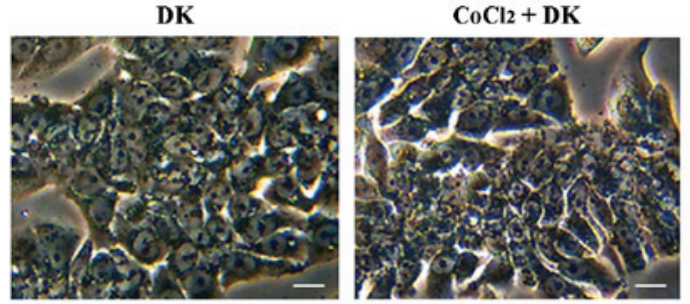

B

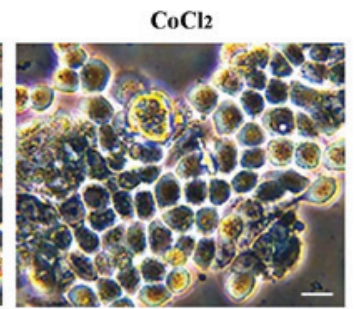

$\mathrm{CoCl}_{2}+\mathrm{DK}$
B

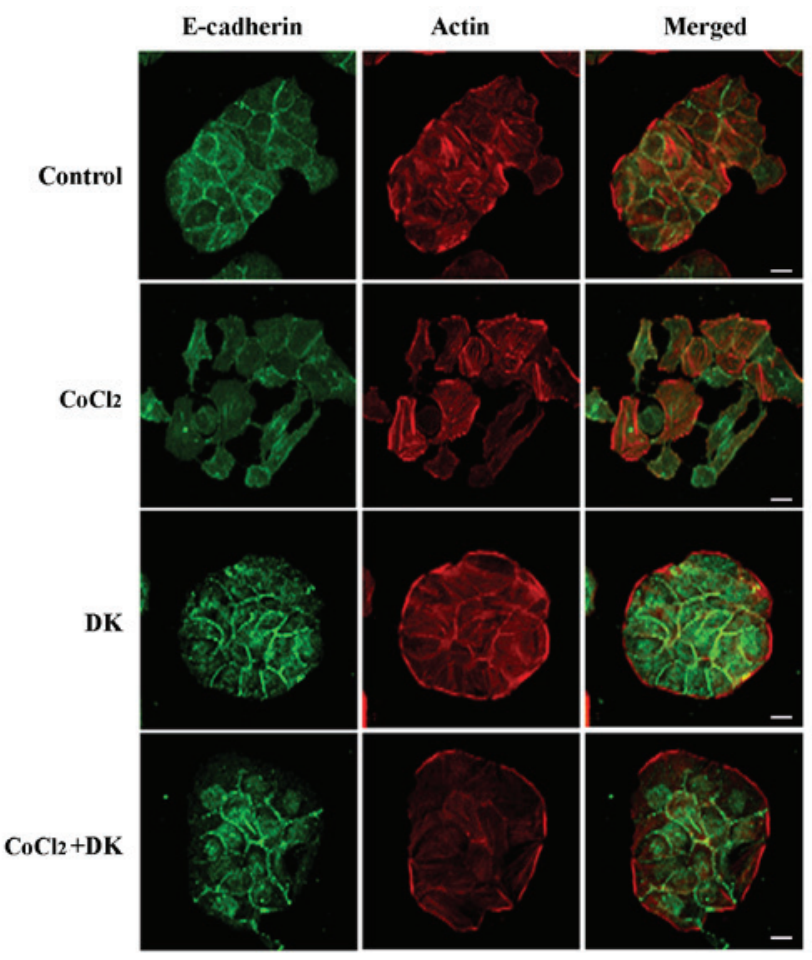

D

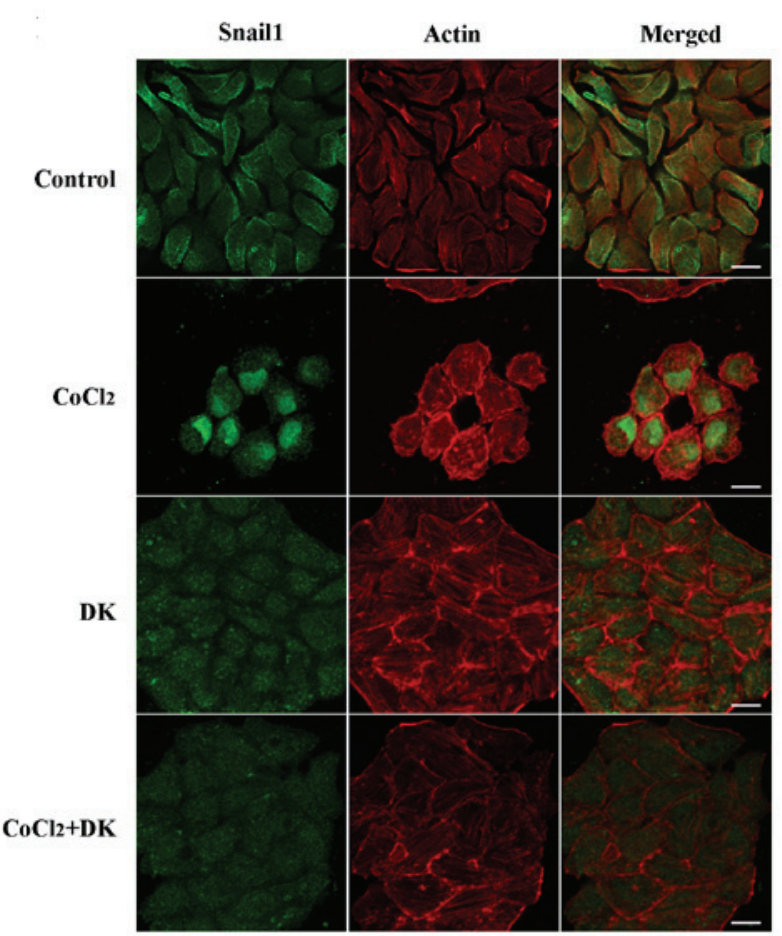

Snail1

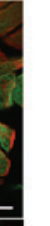 \\ .}

C

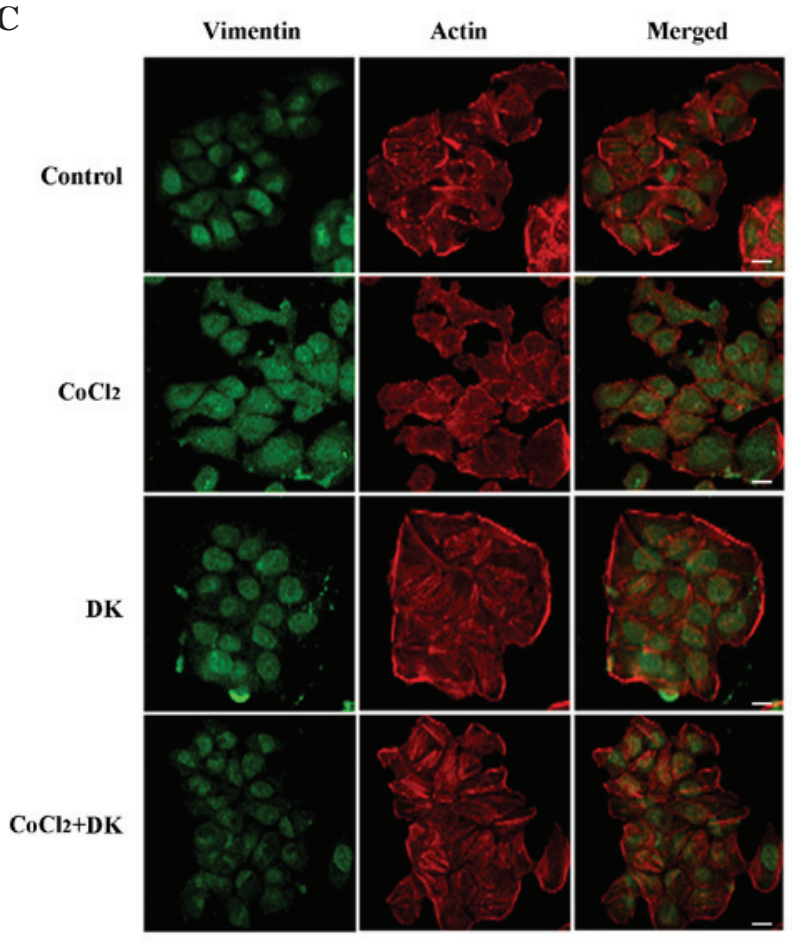

Figure 3. DK inhibited $\mathrm{CoCl}_{2}$-induced EMT-associated phenotypic changes of HT29 cells. (A) HT29 cells (2.0x105 cells/well) were serum starved and incubated in the presence or absence of $50 \mu \mathrm{M} \mathrm{CoCl}_{2}$ for $36 \mathrm{~h}$, followed by treatment with or without $25 \mathrm{mg} / \mathrm{ml} \mathrm{DK}$ for $12 \mathrm{~h}$. Morphological changes of cells were detected by phase contrast microscopy (scale bar, $10 \mu \mathrm{m}$ ). Representative images of all cells were collected after $3 \mathrm{~h}$ treatment with $25 \mathrm{mg} / \mathrm{ml} \mathrm{DK}$. $\mathrm{CoCl}_{2}$ treatment induced changes in intracellular localization of typical EMT marker proteins. Intracellular localization of (B) E-cadherin, (C) vimentin, and (D) Snail1 was determined using antibodies specific to each protein and Alexa Fluor 488 (green) conjugated secondary antibodies. Actin was immunostained using rhodamine phalloidin (red). Cells were visualized by laser confocal scanning microscopy. Representative images from three independent experiments have been presented. Scale bar, $10 \mu \mathrm{m}$. DK, dieckol; EMT, epithelial-mesenchymal transition.

\section{Discussion}

Metastasis is required for tumor progression to occur. Recent developments in early diagnosis and surgical techniques have revealed that $>90 \%$ of mortality in cancer patients is due to the metastatic spread of primary tumors (20). It is of note that in patients with colorectal cancer, $\sim 50 \%$ of patients with an early diagnosis have already developed metastasis. 
A

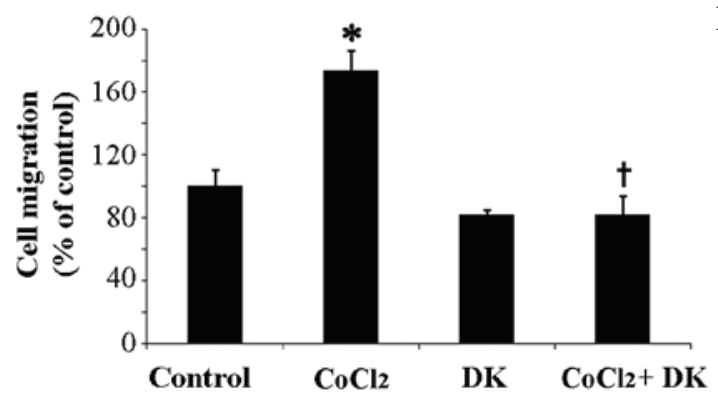

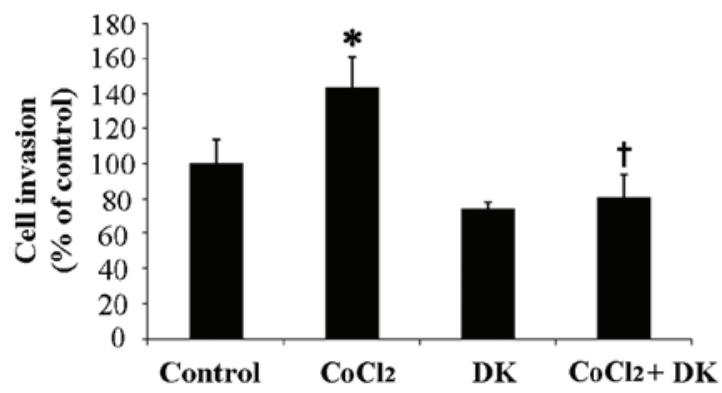

Figure 4. DK decreased $\mathrm{CoCl}_{2}$-induced migration and invasion of $\mathrm{HT} 29$ cells. (A) Inhibitory effects of DK on the CoCl${ }_{2}$-induced migration of $\mathrm{HT}_{2} 9$ cells. Cell migration assays were performed with $\mathrm{HT} 29$ cells incubated in the presence or absence of $50 \mu \mathrm{M} \mathrm{CoCl}_{2}$ and/or $25 \mathrm{mg} / \mathrm{ml} \mathrm{DK}$. Cells that migrated through the pores to the lower surface of the membrane were fixed, stained and counted. Five random microscopic fields were counted in each treatment group. ${ }^{*} \mathrm{P}<0.05$ vs. control; ${ }^{\dagger} \mathrm{P}<0.05$ vs. $\mathrm{CoCl}_{2}$. (B) Invasion assay was performed with $\mathrm{HT} 29$ cells incubated with $50 \mu \mathrm{M} \mathrm{CoCl}_{2}$ and/or $25 \mathrm{mg} / \mathrm{ml} \mathrm{DK}$. All data are presented as the mean \pm standard deviation from three independent experiments. ${ }^{*} \mathrm{P}<0.05$ compared with control; ${ }^{\dagger} \mathrm{P}<0.05$ compared with $\mathrm{CoCl}{ }_{2}$. $\mathrm{DK}, \mathrm{dieckol}$.

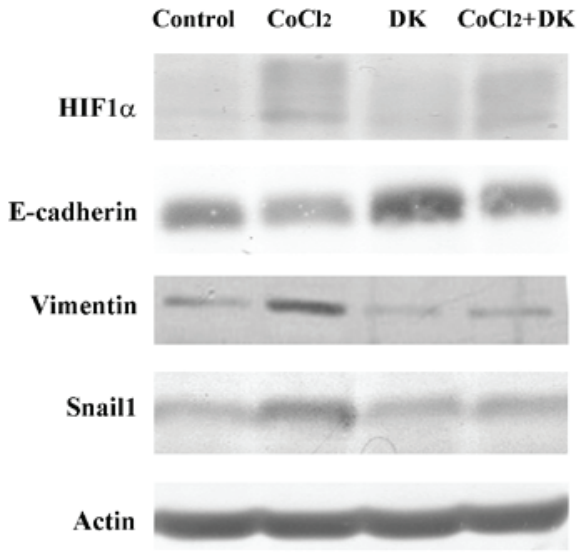

Figure 5. DK suppressed the HIF1 $\alpha$ signaling pathway required for $\mathrm{CoCl}_{2}$-induced EMT in HT29 cells. HT29 cells were incubated in the presence or absence of $50 \mu \mathrm{M} \mathrm{CoCl}_{2}$ and/or $25 \mathrm{mg} / \mathrm{ml}$ DK. Protein expression levels of HIF1 $\alpha$, E-cadherin, vimentin and snail1 in the different treatment groups were analyzed using western blotting. A representative image from three independent experiments has been presented. DK, dieckol HIF1 $\alpha$, hypoxia-induced factor $1 \alpha$; EMT, epithelial-mesenchymal transition.

Colorectal cancer may metastasize to the liver, lung, peritoneum and various other distant organs. The metastasis rates and mortality of colorectal cancer have markedly increased, resulting in it becoming the third most common type of cancer worldwide $(21,22)$. Conventional chemotherapy increases the survival rate of patients with colorectal cancer; however, there is a wide range of acute and long-term side effects that may substantially affect the quality of life of patients. Non-toxic chemotherapeutic agents derived from natural products may be used for future treatment of colorectal cancer.

Dieckol is a natural and non-toxic polyphenol compound and its antioxidant properties have previously been examined $(23,24)$. A previous study revealed the anti-inflammatory and anticancer activities of dieckol are based on the induction of apoptosis and inhibition of aberrant proliferation by oxidative stress (14). The present study demonstrated that dieckol inhibited the hypoxia-induced metastatic properties of tumor cells by the downregulation of intracellular ROS levels and reduction of HIF1 $\alpha$ signaling. $\mathrm{CoCl}_{2}$-induced hypoxia increased ROS generation and promoted EMT in HT29 cells, subsequent treatment with dieckol inhibited hypoxia-induced EMT.
Previous studies have reported that hypoxia-induced EMT occurs downstream of HIF1 $\alpha(25,26)$ and hypoxia-induced intracellular ROS generation activates various signaling components upstream of HIF1 $\alpha$ such as phosphatidylinositol 3-kinase/AKT serine/threonine kinase $1(27,28)$ and mitogen-activated protein kinase (29-31). Expression of the dominant negative HIF1 $\alpha$ mutant, von Hippel-Lindau tumor suppressor, or its silencing has been identified to increase E-cadherin expression (16), whereas E-cadherin RNAi increased the migration and invasion of tumor cells in hypoxic conditions (18), indicating that a HIF1 $\alpha$-dependent downregulation of E-cadherin may be a critical factor for the occurrence of EMT during hypoxia. It has also been previously reported that Snail1, another strong transcriptional repressor of E-cadherin, may be regulated by interaction with HIF1 $\alpha$ (18). Snail1 has been determined to be overexpressed in various types of human cancer (31). The upregulation of Snail1 may subsequently result in decreased E-cadherin levels and ultimately EMT $(18,32)$. HIF1 $\alpha$ silencing has also been identified to affect nuclear localization and activation of Snaill and tumor cell invasion (19). Therefore, it is possible that hypoxia-induced EMT-associated events may be due to the activation of HIF1 $\alpha$ and Snail in conjunction with the reduction of E-cadherin. The findings of the present study clearly supported this hypothesis as the association between the expression of HIF1 $\alpha$ and Snail1, E-cadherin and vimentin in hypoxia-induced invasive tumor cell migration was evident.

In conclusion, the present study provided evidence that hypoxia-induced EMT of HT29 human colorectal cancer cells may be dependent on cellular ROS levels and the HIF1 $\alpha$ signaling pathway. In addition, the results suggested that the natural, non-toxic antioxidant, dieckol, may be considered a novel therapeutic agent for the treatment of metastatic colorectal cancer.

\section{Acknowledgements}

The present study was supported by the Basic Science Research Program through the National Research Foundation of Korea, funded by the Ministry of Education, Science and Technology (grant nos. 2012R1A1A2041500 and 2015R1D1A3A01018506). 


\section{References}

1. Krishnamachary B, Berg-Dixon S, Kelly B, Agani F, Feldser D, Ferreira G, Iyer N, LaRusch J, Pak B, Taghavi P and Semenza GL: Regulation of colon carcinoma cell invasion by hypoxia-inducible factor 1. Cancer Res 63: 1138-1143, 2003.

2. Koga F, Kihara K and Neckers L: Inhibition of cancer invasion and metastasis by targeting the molecular chaperone heat-shock protein 90. Anticancer Res 29: 797-807, 2009.

3. Mendez O, Zavadil J, Esencay M, Lukyanov Y, Santovasi D, Wang SC, Newcomb EW and Zagzag D: Knock down of HIF-1alpha in glioma cells reduces migration in vitro and invasion in vivo and impairs their ability to form tumor spheres. Mol Cancer 9: 133, 2010.

4. Rankin EB and Giaccia AJ: The role of hypoxia-inducible factors in tumorigenesis. Cell Death Differ 15: 678-685, 2008.

5. Giannoni E, Parri M and Chiarugi P: EMT and oxidative stress: A bidirectional interplay affecting tumor malignancy. Antioxid Redox Signal 16: 1248-1263, 2012.

6. Tsai YP and Wu KJ: Hypoxia-regulated target genes implicated in tumor metastasis. J Biomed Sci 19: 102, 2012.

7. Luo Y, He DL, Ning L, Shen SL, Li L and Li X: Hypoxia-inducible factor-1alpha induces the epithelial-mesenchymal transition of human prostatecancer cells. Chin Med J (Engl) 119: 713-718, 2006.

8. Zhang L, Huang G, Li X, Zhang Y, Jiang Y, Shen J, Liu J, Wang Q, Zhu J, Feng X, et al: Hypoxia induces epithelial-mesenchymal transition via activation of SNAI1 by hypoxia-inducible factor $-1 \alpha$ in hepatocellular carcinoma. BMC Cancer 13: 108, 2013.

9. Zhang W, Wu Y, Yan Q, Ma F, Shi X, Zhao Y, Peng Y, Wang J and Jiang B: Deferoxamine enhances cell migration and invasion through promotion of HIF-1 $\alpha$ expression and epithelial-mesenchymal transition in colorectal cancer. Oncol Rep 31: 111-116, 2014.

10. Liu LZ, Hu XW, Xia C, He J, Zhou Q, Shi X, Fang J and Jiang BH: Reactive oxygen species regulate epidermal growth factor-induced vascular endothelial growth factor and hypoxia-inducible factor-1alpha expression through activation of AKT and P70S6K1 in human ovarian cancer cells. Free Radic Biol Med 41: 1521-1533, 2006.

11. Zhao JP, Zhou ZG, Hu HL, Guo Z, Wang T, Zhen GH and Zhang ZX: The relationships among reactive oxygen species, hypoxia-inducible factor 1alpha and cell proliferation in rat pulmonary arterial smooth muscle cells under hypoxia. Sheng Li Xue Bao 59: 319-324, 2007.

12. Catalano V, Turdo A, Di Franco S, Dieli F, Todaro M and Stassi G: Tumor and its microenvironment: A synergistic interplay. Semin Cancer Biol 23: 522-532, 2013.

13. Pettersen EO, Ebbesen P, Gieling RG, Williams KJ, Dubois L, Lambin P, Ward C, Meehan J, Kunkler IH, Langdon SP, et al: Targeting tumour hypoxia to prevent cancer metastasis. from biology, biosensing and technology to drug development: The METOXIA consortium. J Enzyme Inhib Med Chem 30: 689-721, 2015.

14. Lee SH, Park MH, Heo SJ, Kang SM, Ko SC, Han JS and Jeon YJ: Dieckol isolated from Ecklonia cava inhibits alpha-glucosidase and alpha-amylase in vitro and alleviates postprandial hyperglycemia in streptozotocin-induced diabetic mice. Food Chem Toxicol 48: 2633-2637, 2010.

15. Duan W, Chang Y, Li R, Xu Q, Lei J, Yin C, Li T, Wu Y, Ma Q and Li X: Curcumin inhibits hypoxia inducible factor-1 $\alpha$-induced epithelial-mesenchymal transition in HepG2 hepatocellular carcinoma cells. Mol Med Rep 10: 2505-2510, 2014.
16. Krishnamachary B, Zagzag D, Nagasawa H, Rainey $\mathrm{K}$, Okuyama H, Baek JH and Semenza GL: Hypoxia-inducible factor-1-dependent repression of E-cadherin in von hippel-lindau tumor suppressor-null renal cell carcinoma mediated by TCF3, ZFHX1A and ZFHX1B. Cancer Res 66: 2725-2731, 2006.

17. Chan DA and Giaccia AJ: Hypoxia, gene expression and metastasis. Cancer Metastasis Rev 26: 333-339, 2007.

18. Evans AJ, Russell RC, Roche O, Burry TN, Fish JE, Chow VW, Kim WY, Saravanan A, Maynard MA, Gervais ML, et al: VHL promotes E2 box-dependent E-cadherin transcription by HIF-mediated regulation of SIP1 and snail. Mol Cell Biol 27: 157-69, 2007.

19. Cannito S, Novo E, Compagnone A, Valfre di Bonzo L, Busletta C, Zamara E, Paternostro C, Povero D, Bandino A, Bozzo F, et al: Redox mechanisms switch on hypoxia-dependent epithelial-mesenchymal transition in cancer cells. Carcinogenesis 29: 2267-2278, 2008.

20. Christofori G: New signals from the invasive front. Nature 441: 444-450, 2006

21. Boyle P and Ferlay J: Mortality and survival in breast and colorectal cancer. Nat Clin Pract Oncol 2: 424-425, 2005.

22. Naishadham D, Lansdorp-Vogelaar I, Siegel R, Cokkinides V and Jemal A: State disparities in colorectal cancer mortality patterns in the United States. Cancer Epidemiol Biomarkers Prev 20: 1296-1302, 2011.

23. Park SJ and Jeon YJ: Dieckol from ecklonia cava suppresses the migration and invasion of HT1080 cells by inhibiting the focal adhesion kinase pathway downstream of Rac1-ROS signaling. Mol Cells 33: 141-149, 2012.

24. Ko SC, Lee M, Lee JH, Lee SH, Lim Y and Jeon YJ: Dieckol, a phlorotannin isolated from a brown seaweed, ecklonia cava, inhibits adipogenesis through AMP-activated protein kinase (AMPK) activation in 3T3-L1 preadipocytes. Environ Toxicol Pharmacol 36: 1253-1260, 2013.

25. Semenza GL: Hydroxylation of HIF-1: Oxygen sensing at the molecular level. Physiology (Bethesda) 19: 176-182, 2004.

26. Dehne N, Fuhrmann D and Brüne B: Hypoxia-inducible factor (HIF) in hormone signaling during health and disease. Cardiovasc Hematol Agents Med Chem 11: 125-135, 2013.

27. Koshikawa N, Hayashi J, Nakagawara A and Takenaga K: Reactive oxygen species-generating mitochondrial DNA mutation up-regulates hypoxia-inducible factor-1alpha gene transcription via phosphatidylinositol 3-kinase-Akt/protein kinase $\mathrm{C} /$ histone deacetylase pathway. J Biol Chem 284: 33185-33194, 2009.

28. Yan M, Rayoo M, Takano EA, KConFab Investigators and Fox SB: BRCA1 tumours correlate with a HIF-1alpha phenotype and have a poor prognosis through modulation of hydroxylase enzyme profile expression. Br J Cancer 101: 1168-1174, 2009.

29. Lan A, Liao X, Mo L, Yang C, Yang Z, Wang X, Hu F, Chen P, Feng J, Zheng D and Xiao L: Hydrogen sulfide protects against chemical hypoxia-induced injury by inhibiting ROS-activated ERK1/2 and p38MAPK signaling pathways in PC12 cells. PLoS One 6: e25921, 2011

30. Yu D, Li M, Tian Y, Liu J and Shang J: Luteolin inhibits ROS-activated MAPK pathway in myocardial ischemia/reperfusion injury. Life Sci 122: 15-25, 2015.

31. Wang F, Liu S, Xi S, Yan L, Wang H, Song Y and Sun G: Arsenic induces the expressions of angiogenesis-related factors through PI3K and MAPK pathways in SV-HUC-1 human uroepithelial cells. Toxicol Lett 222: 303-311, 2013.

32. Batlle E, Sancho E, Franci C, Dominguez D, Monfar M, Baulida J and Garcia De Herreros A: The transcription factor snail is a repressor of E-cadherin gene expression in epithelial tumour cells. Nat Cell Biol 2: 84-89, 2000. 